ORIGINAL ARTICLE

\title{
Adolescent use of the combined oral contraceptive pill: a retrospective observational study
}

\author{
N Krishnamoorthy, S Ekins-Daukes, C R Simpson, R M Milne, P J Helms, J S McLay
}

Arch Dis Child 2005;90:903-905. doi: 10.1136/adc.2004.059170

See end of article for authors' affiliations

.....................

Correspondence to: Dr J McLay, Department of Medicine and

Therapeutics, The

University of Aberdeen,

Polwarth Buildings,

Foresterhill, Aberdeen

AB25 2ZD, UK; i.mclay@

abdn.ac.uk

Accepted

6 December 2004

Published Online First

26 April 2005

\begin{abstract}
Aims: To determine the extent of combined oral contraceptive use by girls aged 10-16 years in Scotland. Methods: Assessment of combined oral contraceptive prescribing in 35414 girls for the year 1 November 1999-31 October 2000 from data retrieved from 161 primary care practices taking part in the Scottish Programme for Improving Clinical Effectiveness in Primary Care, and from national aggregated data from family planning clinics.

Results: During the study period the oral contraceptive pill (OCP) was prescribed by a primary care physician to 1531 girls $(4.3 \%)$ aged 10-16 years. The age specific prevalence rates per 1000 girls registered with their family doctor rose from $0.9 / 1000$ girls aged 12 years or younger, to $6.9,30,86.3$, and $174.8 / 1000$ for girls aged $13,14,15$, and 16 years respectively. The overall prevalence of combined oral contraceptive prescribing by primary care physicians was $43.2 / 1000$ girls aged $10-16$ years. A further 1765 girls aged 13-16 years obtained a prescription for the OCP from a Scottish family planning clinic, giving an overall prevalence rate for family planning clinic prescribing of 8.0/1000 girls aged 10-16 years. Despite reportedly high levels of sexual activity and teenage pregnancy in this age group, these results confirm that OCP use is relatively low.

Conclusions: The UK has the highest rate of teenage pregnancy in Western Europe, but despite the medical and social concerns about the sexual health of teenagers, the level of oral contraceptive use in this young age group remains low.
\end{abstract}

A lthough the legal age of consent for heterosexual sex within the UK is 16 years of age, the proportion of under-16s indulging in heterosexual intercourse is reported to have increased significantly in the last decade. ${ }^{1-3}$ In Scotland, the prevalence of heterosexual intercourse has been reported to be $15.4 \%$ in 14 year old girls, increasing to $38 \%$ of girls by attainment of their 16th birthday. ${ }^{4}$ Young adults and teenagers are more likely to engage in high risk behaviour, including unprotected sex and multiplicity of sexual partners, ${ }^{4-7}$ and as a result high rates of sexually transmitted infections, and unintended teenage pregnancy represent a significant challenge to western healthcare systems. $^{89}$

The National Survey of Attitudes and Lifestyles II (NATSAL 2000) reported that early age at first intercourse was associated with teenage pregnancy and abortion, ${ }^{3}$ and currently the UK has the highest rate of teenage births in Western Europe. ${ }^{10}{ }^{11}$

The recommended strategy to reduce the incidence of teenage pregnancy in the UK includes specific measures advising teenagers about contraception and the use of contraceptives, together with guidance for health professionals on the prescription, supply, and administration of contraceptives to adolescents. ${ }^{10}$ In an attempt to reduce the high levels of teenage pregnancy in the UK, which is reported to be $8.9 / 1000$ girls aged $13-15$ years, the oral contraceptive is prescribed by both primary care physicians and family planning clinics (FPCs). ${ }^{10}{ }^{12}$ However, the use of FPCs by girls under 16 years of age is anecdotally low, as evidenced by national figures, making the primary care physician the most common source for both advice and prescriptions for the OCP in the youngest and most vulnerable age group. The strategy to prevent teenage pregnancy and sexually transmitted diseases in developed countries such as the UK is to improve access to contraceptive services and to promote safe sex education in early adolescence. ${ }^{6}{ }^{10} 12$ While NATSAL II is a rich source of information on teenage sexuality and contraceptive use in girls over 16 years of age, it does not report on the use of the combined oral contraceptive in the significant number of girls aged 10-16 who are also sexually active. ${ }^{3}$

The aim of the present study was to determine the level of combined oral contraceptive pill prescribing to girls aged 1016 years in Scotland.

\section{METHODS}

In Scotland, women obtain a prescription for the OCP, either from their primary care physician or from an FPC, and to determine the total number of girls prescribed the OCP during the study year, it was necessary to interrogate two separate databases.

\section{Primary care}

Anonymised computerised medical data was collected from 161 primary care practices participating in the Scottish Programme for Improving Clinical Effectiveness in Primary Care (SPICE-pc), using the General Practice Administration System for Scotland software (GPASS), for the period 1 November 1999 to 31 October 2000. The SPICE-pc database, which has been previously shown to be complete, accurate, and to represent the gender, age, and rural and urban mix of the Scottish population, ${ }^{13-16}$ contains demographic, morbidity, and prescribing information for 1132634 patients, including 177752 children 10-16 years of age. Using this database, all females aged 10-16 years, prescribed an oral contraceptive (British National Formulary code 7.3.1) by their primary care physician during the study period were identified. Only the first prescription was counted, and prevalence rates estimated for each age group using the numbers of girls aged 1016 years of age registered with the 161 SPICE-pc practices.

Abbreviations: FPC, family planning clinic; ISD, Information and Statistics Division; OCP, oral contraceptive pill 
Table 1 The prevalence of oral contraceptive pill prescribing in Scottish primary care practices contributing to GPASS

\begin{tabular}{lclc}
\hline & $\begin{array}{l}\text { No. prescribed the } \\
\text { OCP by a primary } \\
\text { care physician }\end{array}$ & $\begin{array}{l}\text { No. of females } \\
\text { registered with } \\
\text { the SPICE-pc } \\
\text { practices }\end{array}$ & $\begin{array}{l}\text { Annual prevalence/ } \\
1000 \text { girls }(95 \% \text { CI) }\end{array}$ \\
\hline Age $(\mathbf{y})$ & 15095 & $0.9(0.6$ to 2.0$)$ \\
13 & 14 & 5075 & $6.9(5.00$ to 9.6$)$ \\
14 & 150 & 5005 & $30.0(15.6$ to 35.1$)$ \\
15 & 447 & 5177 & $86.3(79.0$ to 94.3$)$ \\
16 & 885 & 5062 & $174.8(164.6$ to 185.5$)$ \\
\hline
\end{tabular}

\section{Family planning clinic}

The only other possible source for an OCP prescription in Scotland is from an FPC. Anonymised data, including gender, age, reason for consult, and prescription is collected annually by the Scottish Executive's Information and Statistics Division (ISD) from all FPCs located throughout Scotland. Fully anonymised data for OCP prescriptions supplied by FPCs during the study year for girls aged 10-16 years was supplied by ISD Scotland. Because the ISD data reports national FPC prescribing of the OCP, prevalence rates were estimated using Scottish 1999-2000 Census data for girls aged $10-16$ years of age.

Because an individual is always registered with a GP, the two databases interrogated were not mutually exclusive; however, because of the anonymisation process it was not possible to remove duplicated individuals and consequently the data presented would tend to overestimate the current level of prescribing. Our results however would suggest that the level of duplication is small.

\section{RESULTS}

\section{Primary care (table 1)}

A total of 35414 girls aged 16 years or younger were registered with the 161 primary care practices during the study year, of whom $1531(4.3 \%)$ were issued with a prescription for the OCP. The age specific rates for OCP prescribing in the primary care practices increased from 0.9/ 1000 girls aged 12 years or younger registered with a primary care physician, to $6.9,30,86.3$, and $174.8 / 1000$ for girls aged $13,14,15$, and 16 years respectively (table 1 ). The overall prevalence rate for OCP prescribing in primary care was 43.2/ 1000 girls $10-16$ years of age.

\section{Family planning clinic data (table 2)}

Using Scottish census data for 1999-2000, and OCP prescribing figures for all Scottish FPCs obtained from ISD Scotland, the OCP was prescribed to $1.0 / 1000$ girls aged 13

Table 2 The prevalence of oral contraceptive pill prescribing by Scottish family planning clinics during the study year

\begin{tabular}{|c|c|c|c|}
\hline Age (y) & $\begin{array}{l}\text { No. prescribed } \\
\text { the OCP by an } \\
\text { FPC }\end{array}$ & $\begin{array}{l}\text { No. of females at } \\
\text { that age using } \\
\text { Scottish Census } \\
\text { figures 1999- } \\
2000\end{array}$ & $\begin{array}{l}\text { Annual prevalence/ } \\
1000 \text { girls of that } \\
\text { age }(95 \% \mathrm{Cl})\end{array}$ \\
\hline$>13$ & 9 & 94351 & $0.1(0.005$ to 0.18$)$ \\
\hline 13 & 33 & 31909 & $1.03(0.7$ to 1.5$)$ \\
\hline 14 & 191 & 32214 & $5.9(5.2$ to 6.8$)$ \\
\hline 15 & 497 & 31681 & 15.7 (14.4 to 17.1$)$ \\
\hline 16 & 1035 & 30364 & 34.1 (32.1 to 36.2$)$ \\
\hline
\end{tabular}

years, 5.9/1000 aged 14 years, 15.7/1000 aged 15 years, and 34.1/1000 girls aged 16 years. Throughout Scotland only nine children aged under 13 years were prescribed the OCP from an FPC, giving a prevalence rate of $0.1 / 1000$ girls $10-12$ years of age. The overall prevalence rate for OCP prescribing by Scottish FPCs was 8/1000 girls aged 10-16 years of age.

\section{DISCUSSION}

The twin problems of sexually transmitted disease and teenage pregnancy due to the early age of sexual debut have raised both social and health concerns among policy makers. Epidemiological studies have shed some light on teenage attitudes towards sexual activity and the level of teenage sexuality in the United Kingdom, and it is now widely acknowledged that teenagers are engaging in sexual activity at an increasingly early age. ${ }^{1-5}$

In this study the estimated overall prevalence for primary care OCP prescribing to $10-16$ year old girls was $4.3 \%$, a figure similar to the $4.2 \%$ reported for England and Wales by Rowlands and colleagues. ${ }^{17}$ The figure of $4.2 \%$ reported by Rowlands et al however also took into account prescribing from FPC outlets, and when OCP prescribing rates from Scottish FPCs are added to our figure of $4.3 \%$ (assuming that the two databases are mutually exclusive), the OCP was prescribed to at best $6.6 \%$ of Scottish girls 10-16 years of age during the study year. Although in Scotland it is estimated that $15.4 \%$ of 14 year old girls and $38 \%$ of 15 year old girls are sexually active, ${ }^{45}$ summing the primary care and FPC results obtained in this study would suggest that even in the very best case scenario, only approximately $4 \%$ of 14 year olds, and $10 \%$ of 15 year olds are prescribed the OCP, indicating a significant shortfall between those partaking in sexual activity and those prescribed oral contraception. The fact that young women use their primary care physician, rather than an FPC to obtain a prescription/advice for the OCP is not surprising. In the UK the primary care physician acts as the gatekeeper for the healthcare system, and most are qualified to give contraceptive and gynaecological advice. Furthermore, unlike FPCs which tend to function in a manner similar to drop-in clinics, the population is registered with a primary care practice from early childhood, and such practices are readily accessible, situated locally, and so more accessible to young adolescents.

The relatively low overall uptake of the OCP by sexually active teenagers may be indicative of the fact that few teenagers of this age are aware of the sexual health services provided by primary care physicians or FPCs, or in a position to approach their primary care physician or FPC for contraceptive advice on their own, or are reluctant/embarrassed to do so. ${ }^{18}$ It may also reflect the sporadic nature of sexual activity in this age group and risk taking behaviour, ${ }^{19} 20$ concern about confidentiality, ${ }^{21}{ }^{22}$ or confusion on the part of the adolescent or primary care physician regarding the law as it applies to young children and teenagers. ${ }^{23}$ The importance of these issues has been highlighted by the results of a questionnaire survey of 1045 adolescents 13-15 years of age in which only $68 \%$ of adolescents reported awareness of the sexual health services offered by their primary care physician. Furthermore, 54\% of adolescents believed that they had to be over 16 years of age to access sexual health services and 58\% expressed concerns about a possible lack of confidentiality. ${ }^{22}$ A non-judgmental parental attitude and a good child-parent relationship also appears to be important, both being associated with higher birth control use and a lower probability of both sexual intercourse and pregnancy. ${ }^{23}$ Whatever the reason for not using the OCP there is a clear need to improve adolescent participation, awareness, and access to primary care sexual health services. 


\section{What is already known on this topic}

- A significant number of under 16 year old teenagers are sexually active; the UK has the highest teenage pregnancy rate in Europe

- Contraception is prescribed/supplied by both primary care physicians and family planning clinics

The estimate of contraceptive use made in this study is not fully comprehensive since it does not include information on condom use, which is reportedly used by approximately 50 $60 \%$ of 16 year olds, ${ }^{4524}$ and the use of depot contraceptive preparations, which are reported to be used by $1.9 \%$ of sexually active Scottish girls aged 15 years. ${ }^{4}$

A further important problem when estimating the level of combined oral contraceptive pill use in teenagers is the high discontinuation rate and low levels of compliance. Among adolescents compliance has been reported to be as low as 44$55 \%$, with less than $20 \%$ compliant for a full year. ${ }^{25}{ }^{26}$ In the present study, only the first prescription for the OCP was used to estimate the prevalence rate for OCP use. This methodology, which has been previously reported and is considered to provide a reasonable estimate of OCP use in teenagers, identifies those individuals who are contemplating or are partaking in sexual activity and who have overcome the major hurdle of seeking advice in relation to their sexual activity and health. ${ }^{17}$

A further important consideration is that the OCP may be prescribed for medical reasons other than contraception, such as the treatment of acne and menstrual irregularities. Consequently it is not safe to assume that all OCP prescribing, identified in this study, was for contraception, although prescriptions from an FPC are more likely to be for this indication alone.

\section{Conclusion}

The level of combined oral contraceptive prescribing to teenagers by primary care physicians is likely to be similar throughout Great Britain, and is low when compared with the high degree of sexual activity in young people. The apparent wide disparity between reported sexual activity in young teenagers and low rates of OCP prescribing point to real challenges in sex and relationship education. Cultural attitudes to childhood, and early sexual activity in the context of the current legal framework also confound medical practice in this area.

\section{Authors' affiliations}

N Krishnamoorthy, S Ekins-Daukes, J S McLay, Department of Medicine and Therapeutics, The University of Aberdeen, Polwarth Buildings, Foresterhill, Aberdeen AB25 2ZD, UK

P J Helms, Department of Child Health, The University of Aberdeen, Polwarth Buildings, Foresterhill, Aberdeen AB25 2ZD, UK

C R Simpson, R M Milne, Department of General Practice and Primary Care, The University of Aberdeen, Polwarth Buildings, Foresterhill, Aberdeen AB25 2ZD, UK

Competing interests: none

\section{What this study adds}

- $4.3 \%$ of girls aged $10-16$ are prescribed the OCP by their $\mathrm{G} ; 0.8 \%$ of girls aged $10-16$ are prescribed the OCP by an FPC

- There is a significant shorffall between the number of girls who are sexually active and those prescribed the OCP

\section{REFERENCES}

1 Thomas A, Forster G, Robinson A, et al. National guideline for the management of suspected sexually transmitted infections in children and young people. Arch Dis Child 2003;88:303-11.

2 Johnson A, Wadsworth J, Wellings K, et al. Sexual attitudes and lifestyles. London: Blackwell Scientific, 1994.

3 Wellings K, Nanchahal K, Macdowall W, et al. Sexual behaviour in Britain: early heterosexual experience. Lancet 2001;358:1843-50.

4 Todd J, Currie C, Smith R. Health behaviours of Scottish schoolchildren Technical Report 2: Sexual health in the 1990s. Edinburgh: Research Unit in Health and Behavioural Change, 1999.

5 Wight $D$, Henderson M, Raab G, et al. Extent of regretted sexual intercourse among young teenagers in Scotland: a cross sectional survey. BMJ 2000;320:1243-4.

6 Rivera R, Cabral de Mello, Johnson SL, et al. Contraception for adolescents: social, clinical and service-delivery considerations. Int $J$ Gynaecol Obstet 2001;75:149-63.

7 Johnson AM, Mercer $\mathrm{CH}$, Erens B, et al. Sexual behaviour in Britain: partnerships, practices, and HIV risk behaviours. Lancet 2001;358:1835-42.

8 Fenton KA, Korovessis C, Johnson AM, et al. Sexual behaviour in Britain: reported sexually transmitted infections and prevalent genital Chlamydia trachomatis infection. Lancet $2001 ; 358: 1851-4$.

9 Mcllhaney JS. Sexually transmitted infection and teenage sexuality. Am J Obstet Gynecol 2000;183:334-9.

10 Social Exclusion Unit. Teenage pregnancy, London.http:// www.socialexclusionunit.gov.uk/young_people/teen_preg.htm.

11 Kmietowicz Z. US and UK are top in teenage pregnancy rates. BMJ 2002;324:1354.

12 Information and Statistics Division. Teenage pregnancy in Scotland. 19901999. Health Briefing. Edinburgh: ISD, 2000.

13 Milne RM, Taylor MW, Taylor RJ. Audit of populations in general practice: the creation of a national resource for the study of morbidity in Scottish general practice. J Epidemiol Community Health 1998;52(suppl 1):20S-24S

14 Ekins-Daukes S, Simpson CR, Helms PJ, et al. Burden of corticosteroids in children with asthma in primary care: retrospective observational study. BMJ 2002;324:1374.

15 Ekins-Daukes S, McLay JS, Taylor MW, et al. Antibiotic prescribing for children. Too much and too little? Retrospective observational study in primary care. Br J Clin Pharmacol 2003;56:92-5.

16 Whitelaw FG, Nevin SL, Milne RM, et al. Completeness and accuracy of morbidity and repeat prescribing records held on general practice computers in Scotland. Br J Gen Pract 1996:46:181-6.

17 Rowlands S, Devalia H, Lawrenson R. Use of combined oral contraceptive pill by under 16s. J Fam Plann Reprod Health Care 2001;27:17-19.

18 Jacobson LD, Wilkinson C, Pill R. Teenage pregnancy in the United Kingdom in the 1990s: the implications for primary care. Fam Pract 1995;12:232-6.

19 Moore S, Rosenthal D. Sexuality in adolescence. London: Routledge, 1993.

20 Burack R. Teenage sexual behaviour: attitudes towards and declared sexual activity. Br J Fam Plann 1999;24:145-8.

21 The Bolton Research Group. Patients' knowledge and expectations of confidentiality in primary health care: a quantitative study. Br J Gen Pract 2000;50:901-2.

22 Burack R. Young teenagers attitudes towards general practitioners and their provision of sexual health care. Br J Gen Pract 2000;50:550-4.

23 Jaccard J, Dittus P. Adolescent perceptions of maternal approval of birth control and sexual risk behavior. Am J Public Health 2000;90:1426-30.

24 Coleman L. Comparing contraceptive use surveys of young people in the United Kingdom. Arch Sex Behav 1999;28:255-64.

25 Lara-Torre, Schroeder B. Adolescent compliance and side effects with quick start initiation of oral contraceptive pills. Contraception 2002;66:81-5.

26 Zink TM, Shireman TI, Ho M. High-risk teen compliance with prescription contraception: an analysis of Ohio Medicaid claims. J Pediatr Adolesc Gynecol 2002;15:15-21. 